\title{
A PRÁTICA DOCENTE FRENTE À DESATENÇÃO DOS ALUNOS NO ENSINO FUNDAMENTAL
}

\author{
Teaching practice dealing with students' lack of attention \\ in the primary school
}

Natália Inhauser Rótoli Micaroni (1), Patrícia Abreu Pinheiro Crenitte ${ }^{(2)}$, Sylvia Maria Ciasca ${ }^{(3)}$

\begin{abstract}
RESUMO
Objetivo: Identificar o conhecimento e os conceitos estabelecidos pelos professores sobre a atenção e sua relação com a aprendizagem. Métodos: Foi realizado levantamento e a análise de dados coletados por meio de um questionário com múltipla escolha. O questionário apresentou 4 questões referentes às atitudes práticas do professor frente à desatenção e 8 questões referentes ao conhecimento dos professores sobre a atenção, nas quais foi atribuída uma pontuação. Os dados foram analisados qualitativamente e quantitativamente, por meio de análise estatística descritiva e aplicação do teste não paramétrico de Kolmogorov-Smirnov, para análise da distribuição dos dados. Resultados: Os resultados obtidos nesta pesquisa demonstraram que os professores, embora saibam que há diferença entre Transtorno do Déficit de Atenção (TDA) e desatenção, possuem dificuldades em identificar situações em que ocorre TDA e desatenção, em diferenciar dispersão e distração, em identificar situações que envolvem atenção e os fatores que a limitam. Conclusão: Os professores participantes da pesquisa demonstraram conhecimento inconsistente sobre os desdobramentos da atenção e desatenção, que são elementares para subsidiar uma prática diária.
\end{abstract}

DESCRITORES: Atenção; Ensino; Aprendizagem

(1) Pedagoga; Professora de Ensino Fundamental I; Afiliada à Universidade Estadual de Campinas; Especialista em Psicopedagogia e Neuropsicologia.

(2) Fonoaudióloga; Docente do Departamento de Fonoaudiologia da Faculdade de Odontologia de Bauru da Universidade de São Paulo; Membro do Laboratório de Distúrbios e Dificuldades de Aprendizagem e Transtornos da Atenção e do Grupo de Pesquisa CNPq - Conselho Nacional de Desenvolvimento Científico e Tecnológico: Neurodesenvolvimento, Escolaridade e Aprendizagem da Faculdade de Ciências Médicas da Universidade Estadual de Campinas; Doutora em Ciências Médicas pela Faculdade de Ciências Médicas da Universidade Estadual de Campinas.

(3) Neuropsicóloga; Professora Livre Docente do Departamento de Neurologia da Faculdade de Ciências Médicas da Universidade Estadual de Campinas; Coordenadora do Laboratório de Distúrbios e Dificuldades de Aprendizagem e Transtornos da Atenção e do Grupo de Pesquisa CNPq - Conselho Nacional de Desenvolvimento Científico e Tecnológico: Neurodesenvolvimento, Escolaridade e Aprendizagem da Faculdade de Ciências Médicas da Universidade Estadual de Campinas; Doutora em Neurociência pela Faculdade de Ciências Médicas da Universidade Estadual de Campinas.

Conflito de interesses: inexistente

\section{INTRODUÇÃO}

A desatenção dos alunos vem preocupando educadores e a sociedade em geral, que tendem a relacionar os problemas da falta de atenção com TDAH - Transtorno do Déficit de Atenção e Hiperatividade, cujo pseudo-diagnóstico ${ }^{1}$ é cada vez mais freqüente.

O TDAH é um distúrbio bidimensional ${ }^{2}$ que envolve atenção e hiperatividade/impulsividade ${ }^{3} \mathrm{e}$ apresenta um padrão persistente destes comportamentos, acometendo cerca de apenas 3 a $5 \%$ da população de crianças ${ }^{4,5}$ em idade escolar e que apresentam dificuldade de leitura e escrita. Os principais sintomas são baixo rendimento escolar, dificuldades na realização das tarefas e seguir regras, mas é preciso elucidar o fator principal que diferencia o transtorno, de comportamentos inerentes à idade e aos métodos de ensino a que os alunos são submetidos. No caso do TDAH a causa da falta de atenção é de ordem primária, 
sendo uma incapacidade orgânica de controlar a atenção, enquanto nos casos habituais de desatenção a causa é secundária, pois a dificuldade é comportamental. É preciso considerar que o TDAH apresenta um elevado grau genético ${ }^{6,7}$, de etiologia ainda pouco conhecida, que pode ser modulado por fatores ambientais, como bebida e cigarro durante a gestação.

Assim, o diagnóstico diferencial ${ }^{8}$ é fundamental para descartar possíveis problemas orgânicos dos alunos através de investigação completa e multiprofissional. Afinal os estudos sobre os problemas cognitivos $^{9,10}$ - como déficit de atenção, alterações na memória, de percepção e noções visuo-espaciais, que envolvem leitura, cálculo, capacidade construtiva - constataram que a atenção e as funções executivas controlam as funções cognitivas, surgindo a necessidade de uma avaliação neuropsicológica como auxiliar no esclarecimento da origem de tais déficits.

Ao considerar-se a dificuldade em diagnosticar corretamente o TDAH, o resultado das pesquisas que apontam baixo percentual do diagnóstico patológico somando-se aos fatores genéticos, torna-se estranho pensar que existam tantos alunos portadores do transtorno, fato que motiva a busca de alternativas, para identificação da problemática. Sendo assim se faz necessário uma análise da forma como a atenção é compreendida ${ }^{11}$, podendo ser concebida como condição para aprender, ou efeito de aprendizagem. Desta forma impele-se a visão e o conceito que as escolas e os professores têm sobre educação, formas de ensinar e aprender, que é mais do que mera transmissão de conhecimento e recepção passiva de informações. Porém entre os educadores, pressupõe-se que a atenção focalizada é condição fundamental para aprendizagem e desconhecem que a dispersão ${ }^{1}$ consiste em um deslocamento do foco atencional que impossibilita a concentração, a duração e a consistência da experiência, diferentemente da distração cuja atenção vagueia, fugindo do foco para o qual é solicitado a prestar atenção.

O excesso de informações e estímulos visuais, auditivos, televisivos de forma acelerada, pode desencadear a SPA - Síndrome do Pensamento Acelerado $^{12}$, caracterizada pela velocidade de pensamento, diminuição da concentração, e aumento de ansiedade, e compulsão por novos estímulos. Também gera uma hiperatividade funcional, não genética, que apresentam sintomas tais como diminuição e má qualidade do sono, irritabilidade, fadiga e esquecimento, isto porque o pensamento constantemente acelerado rouba energia vital do córtex cerebral, resultando ainda na perda de memória, que é bloqueada pelo cérebro no intuito de protegê-lo de um colapso, diminuindo o consumo exagerado dessa energia. Como resultado há um aumento da agitação motora e baixo rendimento escolar.

Ainda hoje, o modelo de educação nas escolas brasileiras, mesmo que de forma subliminar, está baseado em um processo de ensino aprendizagem centrado no professor, esperando-se que o aluno mantenha o foco atencional ao detentor do saber. Porém o professor não é o único responsável por tal problemática, pois há uma trajetória político educacional que permeia toda a base da educação, desde a formação dos educadores ${ }^{13}$, perpassando por mau investimento técnico, didático, pedagógico. $\mathrm{O}$ resultado tem se tornado desastroso, pois os professores acabam contornando os problemas sem embasamentos teóricos que expliquem o motivo dos mesmos, refletindo diretamente na qualidade e quantidade das informações que recebem, bem como na aplicação de tais conhecimentos voltada a uma prática docente mais eficaz.

Portanto, com base no que foi exposto, o objetivo do presente trabalho foi identificar o conhecimento e os conceitos estabelecidos pelos professores sobre a atenção e sua relação com a aprendizagem

\section{MÉTODOS}

Trata-se de um estudo transversal desenvolvido em uma amostra de 30 professores, com faixa etária entre 20 e 50 anos, de ambos os sexos, que atuam de $1^{\circ}$ ano ao $9^{\circ}$ ano do Ensino Fundamental, em uma escola da rede particular, com tempo de atuação que variam entre dois e vinte anos de profissão.

Como critério de inclusão, os professores deveriam estar atuando em sala de aula, na escola referida, no ano letivo de 2007, no qual a pesquisa foi realizada. Foram excluídos aqueles professores que trabalham na escola, mas não desempenham função docente ou que se negaram a assinar o Termo de Consentimento Livre e Esclarecido, conforme Resolução 196/96, Conselho Nacional de Saúde 1996.

O instrumento utilizado para identificar o conhecimento dos professores em relação à problemática da desatenção dos alunos em sala de aula, nesta pesquisa, foi o questionário com múltiplas escoIhas. Após essa etapa, com os dados analisados realizou-se a comparação deste com a literatura encontrada.

Como ainda não existem questionários elaborados para os objetivos descritos, elaborou-se um questionário específico. Tal elaboração foi realizada na tentativa de colher dados que colaborassem para um conhecimento mais amplo sobre a prática 
dos professores em sala de aula, em relação à desatenção dos alunos, bem como suas concepções sobre a atenção.

O procedimento foi realizado através da apresentação do questionário, em data definida pela direção da escola, que foram distribuídos e recoIhidos imediatamente.

O questionário, conforme Figura 1, abordou 12 questões de múltipla escolha e contemplou duas categorias: de prática profissional (as quais abordaram aspectos relativos às atitudes mais freqüentes frente à desatenção dos alunos, diante de situações vivenciadas em sala de aula) e de conhecimento dos professores sobre atenção. A distribuição da pontuação de cada questão encontra-se na Figura 1.

Para verificar a adequação do questionário, foi realizado um projeto piloto, aplicado em 10 professores de uma outra amostra, ou seja, composta por professores que não eram sujeitos da presente pesquisa. Com o resultado constatou- se a necessidade de realizar algumas modificações no vocabulário, tornando-o mais simples para a compreensão dos professores, pois havia sido utilizada uma linguagem técnica, dificultando a compreensão dos professores.

O trabalho foi submetido ao Comitê de Ética da Faculdade de Ciências Médicas da Universidade Estadual de Campinas, com parecer Cep: $\mathrm{n}^{\circ}$. 952/2007 - CAAE: 4027.0.000.146-07;

Os resultados deste estudo foram submetidos à análise quantitativa e qualitativa. $A$ análise quantitativa foi realizada devido à atribuição de uma pontuação nas questões referentes ao conhecimento dos professores sobre a atenção (questões 5 à 12), sendo apresentado o desempenho dos professores em cada questão e no total das questões, sendo utilizada análise estatística descritiva. Nas perguntas em que não atribuiu-se pontuação, referentes à praticado professor frente à desatenção dos alunos (questões 1 à 4) foi realizada uma análise qualitativa das respostas.

Para a análise quantitativa, utilizou-se 0 programa estatístico PASW Statistics 18, o qual forneceu a média, mediana e o desvio padrão das questões, e ainda, foi foi aplicado o teste nãoparamétrico de Kolmogorov-Smirnov para determinação da curva de normalidade da distribuição dos resultados.

\section{RESULTADOS}

Em relação às questões que abordam a prática dos professores, os resultados obtidos revelaram que na questão sobre a desatenção dos alunos, estar relacionada ou não com desempenho menor que a média da classe (Questão 1), 18 professores (60\% da amostra) revelaram que acreditam que há relação e 12 professores (40\%) responderam não haver relação da desatenção com desempenho escolar inferior.

Na Questão 2, 15 professores (50\%) acreditam que o aluno desatento é aquele que não participa, nem se envolve com a atividade proposta; dos professores restantes, 11 (37\%) analisam como desatento 0 aluno que não focaliza $\circ$ professor (Tabela 1).

Quanto às atitudes do professor em relação aos alunos desatentos durante suas explicações (Questão 3), 18 professores (60\%) responderam que tentam envolver os alunos através da problematização do assunto; 7 (23\%) direcionam perguntas ao aluno; $1(3 \%)$ fala mais alto e anda pela classe; $1(3 \%)$ chama a atenção do aluno diretamente e 3 $(10 \%)$ alegam tomar outras atitudes tais como: diminuição do tom de voz, interrupção da fala até que os alunos percebam, chama a atenção de forma coletiva, motiva os alunos como um todo.

Em relação ao que os professores acreditam que seja mais importante para o bom desempenho do aluno (Questão 4), 18 professores (60\%) concordam que o aluno deve participar, mesmo que dê respostas erradas; apenas 6 professores $(20 \%)$ acreditam que o aluno deva usar sistema de atenção e desatenção sem perder o foco do assunto; 3 professores (10\%) acreditam que o aluno deva manter atenção focalizada e outros 3 $(10 \%)$ que o aluno deva questionar.

No que se refere às questões que abordaram ao conhecimento dos professores sobre atenção, na Questão 5, 29 professores (97\%) concordam que há diferença entre o Transtorno de Déficit de Atenção e desatenção.

Analisando a Tabela 2, verificou-se que na diferenciação das atitudes de aluno, que podem sugerir TDA (Transtorno do Déficit de Atenção) ou simplesmente desatenção (Questão 6), 23 professores $(77 \%)$ consideram que o aluno que não para sentado e se contorce o tempo todo apresenta TDA. Bem como 19 professores (63\%) alegam compreender que também, apresentam TDA, os alunos que tem dificuldade em manter-se atento. Para 15 professores (50\%), o aluno que parece não ouvir quando Ihe dirigem a palavra também apresenta TDA. Ainda, 17 professores (57\%) concordam que seja simplesmente desatenção quando o aluno não consegue controlar sua atenção.

Para identificar ações que envolvem atenção e não envolvem atenção (Questão 7), 29 professores $(97 \%)$ responderam que solucionar problemas envolve atenção e 1 (3\%) não soube responder; 18 professores $(60 \%)$ concordam que para ações 
1) Baseado em sua experiência profissional, você considera que toda criança desatenta apresenta um desempenho escolar inferior ao da média da classe?

( ) $\operatorname{SIM}($ ) NÃO

2) Das situações listadas abaixo, identifique de acordo com sua prática diária, qual considera desatenção de seu aluno, assinalando a alternativa:

( ) Quando o aluno está trabalhando, mas está conversando com o colega.

( ) Quando você está explicando uma matéria ou passando alguma orientação e o aluno não está olhando em sua direção.

( ) Quando você propõe uma atividade e o aluno não participa, nem se envolve.

( ) Quando numa atividade em grupo, o aluno não se manifesta.

3) Numa situação em sala de aula, em que você está explicando a matéria e percebe que alguns alunos, na sua visão, estão desatentos, qual seria sua principal atitude?

( ) Começa a falar mais alto e a andar pela classe.

( ) Chama a atenção diretamente, dos alunos em questão.

( ) Faz perguntas relacionadas ao tema que está abordando, direcionando-as aos tais alunos.

( ) Tenta envolver os alunos de forma a chamá-los a problematizar o assunto que está sendo trabalhado.

( ) Outras Atitudes. Exemplifique:

4) Levando em conta sua fundamentação pedagógica e sua postura prática, o que você considera mais importante para o bom desempenho do aluno:

( ) Que ele apresente uma atenção focalizada durante as aulas;

( ) Que ele questione suas colocações;

( ) Que ele participe mesmo dando respostas que não seriam previamente estabelecidas como corretas;

( ) Que o aluno utilize um sistema de atenção / desatenção, sem perder o foco do tema que está sendo desenvolvido.

5) Para você há diferença em TDA (Transtorno do Déficit de Atenção) e desatenção? 1 ponto

( ) SIM ( ) NÃO

6) Identifique as situações abaixo, utilizando a letra T para TDA(Transtorno do Déficit de Atenção) e a letra D para desatenção. 4 pontos

( ) Dificuldade do aluno na capacidade de manter-se atento durante a aula.

( ) Dificuldade do aluno em controlar a atenção, quando há interferências de estímulo, como outros colegas conversando, ou ruídos externos.

( ) O aluno parece não ouvir quando se fala diretamente com ele.

( ) O mexe-se e contorce-se na cadeira o tempo todo, ou não pára sentado.

7) Analise as ações abaixo e responda EA quando achar que a ação envolve atenção e NE para ações que não envolvem atenção. 4 pontos

( ) Solucionar problemas.

( ) Andar, sentar, deitar. ( ) Tomar decisões.

( ) Responder perguntas simples, como: qual é a cor que mais gosta.

8) Para você atenção é: 1 ponto

( ) Reação ( ) Sintoma ( ) Comportamento ( ) Capacidade

9) Analise as alternativas abaixo sinalize se as mesmas limitam a atenção, utilizando a letra S para: SIM e a letra $\mathbf{N}$ para $N \tilde{A} O .8$ pontos
( ) Motivação
( ) Memória
( ) Focalizaçlão
( ) Resistência
( ) Percepção
( ) Rotina
( ) Velocidade de pensamento
( ) Seleção de informação 
10) Observe as situações abaixo e coloque DP para o que considerar dispersão e DT para o que considerar distração: 3 pontos

( ) Durante explicação, um aluno folheia o livro da matéria, conversa rapidamente com o colega ao lado, e quando o professor faz uma pergunta, ele responde sobre o tema que estava sendo abordando, porém sem muita consistência em sua resposta.

( ) Enquanto a aula está sendo explicada, um aluno fica olhando o tempo todo para o professor, não conversa com os colegas, mas quando precisa realizar a tarefa solicitada não sabe do que se trata.

( ) Em um trabalho em grupo, um dos alunos fica fazendo gracinhas, conversando, e quando o professor chega perto, começa a compartilhar com os colegas sobre o tema que estão trabalhando.

11) Na sua visão de professor, considera a possibilidade de que haja concentração sem focalização e focalização sem concentração? Então assinale com um $\mathbf{X}$ em que situação há maior chance do aluno aprender o conteúdo a partir de sua intervenção em sala de aula: 1 ponto

( ) O aluno passa a aula toda sentado de lado mexendo no caderno do colega, anda pela sala de aula, mas quando o professor pergunta algo, o aluno respondeu corretamente.

( ) Durante um trabalho em grupo um aluno fica o tempo todo olhando para os textos e para os colegas que estão debatendo sobre o tema, mas quando é questionado , não consegue opinar sobre suas hipóteses.

12) Leia as afirmações abaixo e coloque $\mathbf{V}$ para o que considerar verdadeiro e $\mathbf{F}$ para falso: $\mathbf{4}$ pontos

( ) É fundamental para o sucesso na aprendizagem, que o aluno seja capaz de manter-se atento a um foco determinado, durante as aulas.

( ) Para estar atento é imprescindível que o aluno esteja concentrado e focalizado no tema desenvolvido durante a aula.

( ) Num processo em que o aluno é sujeito de sua aprendizagem, é possível que um ato de atenção/ desatenção esteja contribuindo para a melhor compreensão do aluno.

( ) A desatenção indica que o aluno apresenta um Transtorno de Déficit de Atenção (TDA)

Figura 1 - Questionário

Tabela 1 - Atitudes de Desatenção dos Alunos

\begin{tabular}{ccc}
\hline Alternativas & Freqüência & Percentual \\
\hline A & 2 & $7 \%$ \\
B & 11 & $37 \%$ \\
C & 15 & $50 \%$ \\
D & 1 & $3 \%$ \\
E & 1 & $3 \%$ \\
TOTAL & 30 & $100 \%$ \\
\hline
\end{tabular}

A - Aluno que trabalha, mas conversa com colega.

B - Aluno que não focaliza o professor.

C - Aluno que não participa, nem se envolve.

$D$ - Aluno que não se manifesta.

E - Não souberam responder

Tabela 2 - Diferenciação atitudinais entre Transtorno e Desatenção

\begin{tabular}{cccccccc}
\hline Alternativas & $\begin{array}{c}\text { Transtorno } \\
\text { (T) }\end{array}$ & $\%$ (T) & $\begin{array}{c}\text { Desatenção } \\
\text { (D) }\end{array}$ & $\%$ (D) & Não sabe & \% N.S. & TOTAL \\
\hline A & 19 & $63 \%$ & 10 & $33 \%$ & 1 & $3 \%$ & 30 \\
B & 12 & $40 \%$ & 17 & $57 \%$ & 1 & $3 \%$ & 30 \\
C & 15 & $50 \%$ & 14 & $47 \%$ & 1 & $3 \%$ & 30 \\
D & 23 & $77 \%$ & 6 & $20 \%$ & 1 & $3 \%$ & 30 \\
\hline
\end{tabular}

A - Incapacidade para manter atenção

B - Dificuldade em controlar atenção

C - Parece não ouvir quando Ihe dirigem a palavra

D - Mexe-se e não pára sentado. 
como: andar, sentar e deitar não envolvem atenção, 11 professores (37\%) acreditam que envolve atenção e 1 (3\%) não soube responder; 29 professores (97\%) alegam que tomar decisões envolve atenção e 1 (3\%) não soube responder; 18 professores $(60 \%)$ consideram que responder perguntas simples, como qual a cor preferida, envolve atenção, 11 professores (37\%) discordam afirmando que não envolve atenção, e 1 (3\%) não soube responder.

Conforme a Tabela 3, na Questão 8, verificouse que 20 professores (67\%) responderam que atenção é uma reação, e apenas 5 professores $(17 \%)$ compreendeu que se trata de um comportamento. O restante dividiu suas opiniões, definindo atenção como capacidade ou sintoma.

Ao analisarem situações que poderiam limitar a atenção (Questão 9), 18 professores (60\%) acreditam que a motivação, a memória e a percepção limitam a atenção, sendo que 12 (40\%) discordam, alegando que não limitam; 22 professores (73\%) afirmam que a focalização limita a atenção e 8 $(27 \%)$ discordam desta opinião; 16 professores (53\%) opinaram que a resistência limita a atenção e $14(47 \%)$ dizem que não limita; 13 professores (43\%) alegam que a focalização limita a atenção, mas 17 (57\%) não compartilham da mesma opinião; 20 professores $(67 \%)$ responderam que a seleção de informações é um fator que limita a atenção, e 10 (33\%) responderam que não é um fator limitador; 16 professores $(53 \%)$ concordam que a rotina contribui com a limitação da atenção, contra 14 (47\%) que discordam dessa opinião.
Ao distinguirem situações que são consideradas dispersão e distração (Questão 10), como ilustra a Tabela 4, a grande maioria (24 professores, sendo $80 \%$ da amostra) demonstraram que confundiram as atitudes de dispersão e distração de seus alunos.

A partir da possibilidade de focalização sem concentração e vice-versa (Questão 11), quando questionado em quais situações os alunos têm mais chances de aprender, 24 professores (80\%) responderam ter maior chance de aprendizagem o aluno que apesar de andar pela classe, mexer em seus pertences e conversar, quando questionado sabe responder adequadamente. Para 6 professores (20\%), o aluno considerado quieto, aparentemente olhando para os livros, mas não sabe expressar opinião nem elaborar suas hipóteses, possui maior chance de aprender,

$\mathrm{Na}$ Questão 12, ao analisar-se as alternativas, 18 professores $(60 \%)$ acreditam que é verdadeira a afirmação de que o sucesso na aprendizagem depende da focalização do aluno e manutenção da atenção, contra 12 (40\%) que discordam; 20 professores $(67 \%)$ alegam que seja verdadeiro que para estar atento é imprescindível que o aluno esteja concentrado e focalizado no tema, e 10 (33\%) consideram a afirmação falsa; 16 professores $(53 \%)$ consideram verdadeiro que no processo de aprendizagem é possível um sistema de atenção/ desatenção que contribua para a compreensão do aluno; 26 professores $(87 \%)$ relataram ser falsa a afirmação de que desatenção é sinônimo de TDA (Transtorno do Déficit de Atenção) contra 4 (13\%) que acreditam ser verdadeira.

Tabela 3 - Identificação do que é atenção

\begin{tabular}{ccc}
\hline Alternativas & Freqüência & Percentual \\
\hline A & 20 & $67 \%$ \\
B & 1 & $3 \%$ \\
C & 5 & $17 \%$ \\
D & 4 & $13 \%$ \\
TOTAL & 30 & $100 \%$ \\
\hline
\end{tabular}

A - Reação; B - Sintoma; C - Comportamento; D - Capacidade

Tabela 4 - Diferenciação de Dispersão (DP) e Distração (DT)

\begin{tabular}{cccccc}
\hline Alternativas & Dispersão & $\%$ (DP) & Distração & $\%$ (DT) & Total \\
\hline A & 8 & $27 \%$ & 22 & $73 \%$ & 30 \\
B & 26 & $87 \%$ & 4 & $13 \%$ & 30 \\
C & 5 & $17 \%$ & 25 & $83 \%$ & 30 \\
\hline
\end{tabular}

A- Aluno que conversa e folheia livros durante a aula

B- Aluno com olhar focalizado no professor, mas não focado na aula.

C- Aluno que no trabalho em grupo brinca, mas quando o professor se aproxima começa a trabalhar. 
A Tabela 5 ilustra a média da pontuação dos professores nas questões referentes ao conhecimento sobre a atenção (Questões 5 à 12), bem como a mediana, o desvio padrão, porcentagem de professores que acertaram totalmente a questão e o resultado do teste estatístico de KolmogorovSmirnov, o qual foi aplicado para testar se houve distribuição normal das respostas em cada questão e no total das questões. De acordo com esta tabela, pode-se observar que a questão 5 (referente à diferenciação entre TDA e desatenção) apresentou um maior número de professores que a acertaram (96,70\%). Já a questão 6 (referente à identificação de TDA e desatenção) foi a que teve um menor número de acerto da questão, pois nenhum professor a acertou totalmente. Apenas 6,67\% dos professores identificaram adequadamente os fatores que limitam a atenção (Questão 9). Um número baixo de professores (10\%) conseguiu identificar as situações de dispersão e distração (Questão 10). Somente 16,67\% dos professores foram capazes de identificar a atenção como um comportamento (Questão 8). Quase a metade dos professores (43\%) foi capaz de identificar adequadamente as situações que envolvem atenção (Questão 7).

Em relação ao desempenho no total das questões pelos professores, houve uma média de acerto de 15,07 , e mediana igual a 15 , demonstrando que metade dos sujeitos obteve pontuação abaixo de 15 , e a outra metade, obteve pontuação maior que 15 , no total de pontos do questionário.

O gráfico 1 mostra a distribuição normal da amostra (de acordo com o teste estatístico nãoparamétrico de Kolmogorov-Smirnov) no total de pontos obtidos no questionário.

Tabela 5 - Pontuação obtida nas questões referentes ao conhecimento dos professores sobre a atenção

\begin{tabular}{ccccccc}
\hline Questão & $\begin{array}{c}\text { Total } \\
\text { Máximo } \\
\text { de Pontos }\end{array}$ & Média & Mediana & $\begin{array}{c}\text { Desvio } \\
\text { Padrão }\end{array}$ & $\begin{array}{c}\text { Porcentagem de } \\
\text { professores } \\
\text { que acertaram } \\
\text { totalmente a questão }\end{array}$ & $\begin{array}{c}\text { Sig. (Teste de } \\
\text { Kolmogorov- } \\
\text { Smirnov) }\end{array}$ \\
\hline $\mathbf{5}$ & 1,00 & 0,97 & 1,00 & 0,183 & $96,70 \%$ & $\mathbf{0 , 0 0 0}$ \\
$\mathbf{6}$ & 4,00 & 2,00 & 2,00 & 0,910 & $0,00 \%$ & 0,076 \\
$\mathbf{7}$ & 4,00 & 3,17 & 3,00 & 0,950 & $43,33 \%$ & 0,058 \\
$\mathbf{8}$ & 1,00 & 0,17 & 0,00 & 0,379 & $16,67 \%$ & $\mathbf{0 , 0 0 0}$ \\
$\mathbf{9}$ & 8,00 & 4,63 & 5,00 & 1,691 & $6,67 \%$ & 0,112 \\
$\mathbf{1 0}$ & 3,00 & 0,60 & 0,00 & 0,968 & $10,00 \%$ & $\mathbf{0 , 0 0 1}$ \\
$\mathbf{1 1}$ & 1,00 & 0,80 & 1,00 & 0,407 & $80,00 \%$ & $\mathbf{0 , 0 0 0}$ \\
$\mathbf{1} 2$ & 4,00 & 2,73 & 3,00 & 0,868 & $16,67 \%$ & 0,140 \\
Total & 26,00 & 15,07 & 15,00 & 2,164 & $0,00 \%$ & 0,772 \\
\hline
\end{tabular}

${ }^{*}$ Quando sig<0,05, rejeita-se a hipótese nula H0 (a distribuição da amostra segue a distribuição normal) e aceita-se H1 (a distribuição da amostra não segue destribuição normal).

Gráfico 1 - Distribuição normal da amostra, no total de pontos obtidos no questionário, de acordo com o teste estatístico de Kolmogorov-Smirnov

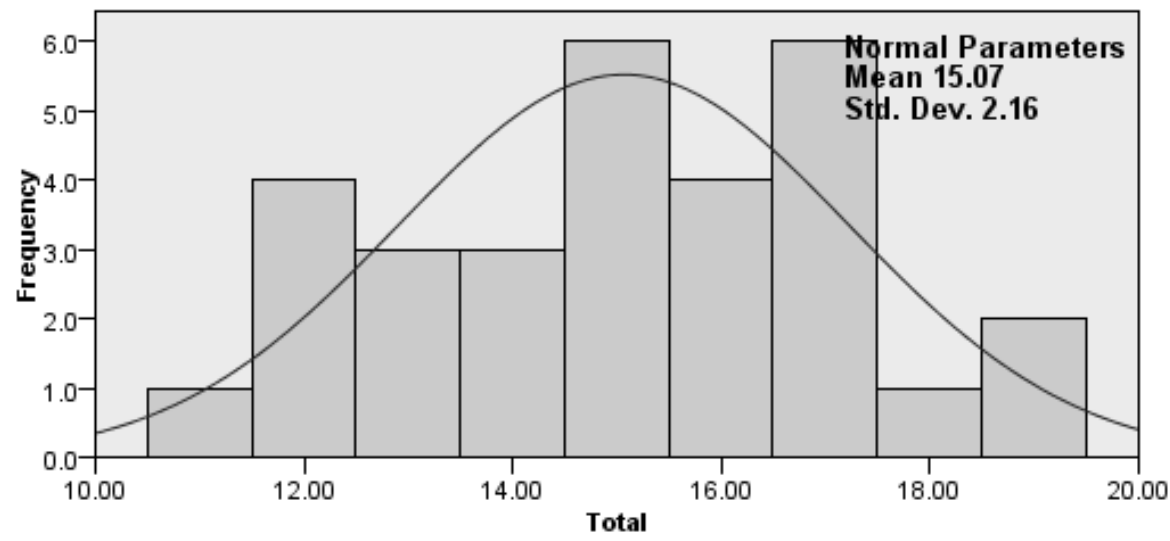




\section{DISCUSSÃO}

Ao analisar os dados obtidos, observou-se que quando o tema abordado é a desatenção, entendida simplesmente do ponto de vista comportamental, as opiniões dos professores são divididas, porém de forma proporcional, no tocante ao desempenho escolar. Em média, metade dos professores compreende a desatenção relacionada com a falta de envolvimento e participação dos alunos. Note-se que tal desatenção não significa necessariamente resultado de diagnóstico de TDAH ${ }^{14}$.

A prática pedagógica precisa abrir espaço para vivências dialógicas, propiciando a problematização, levantamento de hipóteses, interação entre os pares e o meio, e ainda experiências práticas, que envolvam situações de elaboração de seu próprio conhecimento ${ }^{11}$, colaborando com a produção da consciência e memória, trocando a dispersão pela atenção consciente. Também é importante ressaltar que a vivência na escola deve perpassar por um processo de significação ${ }^{15}$ despertando o desenvolvimento integral do indivíduo.

Destaca-se que ao responderem algumas questões, baseados em sua prática diária, foram encontradas respostas sugestivas de que os professores não conseguem ter clareza da diferença entre atenção e desatenção, nem que o sistema atenção/ desatenção faz parte do processo de aprendizagem e de construção do conhecimento.

Dos professores que responderam ao questionário, a maioria, ou seja, 97\%, afirmou que há diferença entre desatenção e TDA $^{14}$ (Transtorno do Déficit de Atenção) e nas situações exemplificadas no questionário, conseguiram diferenciá-las. Também afirmaram que desatenção não é sinônimo de TDA (Transtorno do Déficit de Atenção). Tais resultados são contraditórios com a literatura e com a discussão nacional, em torno da Educação Básica no Brasil. Afinal na maioria das vezes, as dificuldades escolares, são tratadas como sendo de ordem orgânica, sugerindo-se pseudos-diagnósticos de transtornos tendo em destaque o Transtorno do Déficit de Atenção, que acomete ${ }^{4,5}$, cerca de apenas 3 a $5 \%$ da população de crianças em idade escolar e que apresentam dificuldade de leitura e linguagem.

As pesquisas governamentais, baseadas no resultado do Sistema de Avaliação da Educação Básica (2003) aliado ao que observa-se cotidianamente nas escolas, apontam um quadro preocupante no desempenho da leitura e escrita entre os alunos do Ensino Fundamental ${ }^{16}$, tais elementos favorecem as pesquisas pautadas em hipóteses de que as crianças com dificuldades de leitura e escrita possam ter algum atraso no desenvolvimento neuropsicológico. É preciso considerar que há pouca atençã ${ }^{17}$ e pesquisas sobre os distúrbios de aprendizagem, déficit de atenção, distúrbios específicos de leitura e escrita e outros transtornos correlacionados. Assim é preciso cautela para diagnosticar, rotular e até mesmo encaminhar alunos para avaliação e intervenção profissional.

Os educadores em geral, mas principalmente os professores precisam ter clareza de que o Transtorno do Déficit de Atenção é um distúrbio orgânico, crônico ${ }^{18}$, neuropsiquiátrico mais comum na infância ${ }^{19} \mathrm{e}$ mais freqüente nas escolas, representando o primeiro motivo de consultas a serviços de saúde mental infantil ${ }^{20}$. As causas do TDAH ainda estão em pesquisas, mas na maioria das crianças pesquisadas e que são portadoras do transtorno, não foi evidenciado lesões cerebrais amplas nem mesmo doenças do sistema nervoso central $(\mathrm{SNC})^{21}$, assim como o contrário também ocorre, pois nem todas as crianças com lesões cerebrais apresentam sintomas de TDAH.

Ao serem questionados sobre o conhecimento do que é atenção, nota-se que poucos professores entendem que a atenção trata-se de um comportamento, sendo que a maioria considera uma reação. Isto denota que também não há conhecimento de que, no caso de crianças que não possuem nenhum transtorno, é possível aprender a controlar a atenção. Para aprender a controlar tal comportamento se faz necessária uma parceria entre família e escola no envolvimento desse processo, focalizando a dimensão do autocontrole e a expressão afetiva $^{7}$. No princípio geral de manejo na escola ${ }^{22}$ sugere-se que os professores utilizem: regras claras e breves, com reforço visual; sistema de recompensas e punições rápidas, imediatas, bem planejadas e organizadas; respostas pelo cumprimento das regras; recompensas e incentivos devem ser preferenciais, pois as punições não colaboram no controle do comportamento; processo de antecipação, ou seja, sempre que iniciar uma nova ação revisar e recordar as regras, explicitando as recompensas e punições; dar continuidade ao plano de aula assim que começar, não interromper; pensar em voz alta e para frente, incentivando os alunos desatentos a fazerem o mesmo.

Quanto aos fatores que contribuem com a limitação da atenção, observamos que as opiniões se dividiram novamente, demonstrando que em metade das alternativas que abordavam tais fatores, os professores não conseguiram discernir corretamente, reforçando a hipótese de insuficiência de conhecimento e conseqüentemente conduz a uma concepção inadequada sobre a atenção, quando considerada condição para aprender ${ }^{11}$ e não como efeito de aprendizagem. Desta forma impele-se a 
visão e o conceito que as escolas e os professores têm sobre educação, formas de ensinar e aprender.

Nas questões em que foram exemplificadas situações que evidenciam sinais de dispersão e distração, as respostas demonstraram que não há clareza sobre o assunto entre os professores. Porém é necessário que os educadores compreendam que dispersão ${ }^{1}$ consiste em um deslocamento do foco atencional e que por sua vez impossibilita a concentração, a duração e a consistência da experiência. Ao passo que, distração é um funcionamento em que a atenção vagueia, fugindo do foco para o qual é solicitado a prestar atenção prevalecendo pensamentos fora do local em que o indivíduo encontra-se.

Os professores, em sua maioria, demonstraram concordância de haver a possibilidade de focalização sem concentração e vice-versa no processo de ensino aprendizagem. De acordo com esta visão, o aluno que se mexe e conversa com os colegas, mas quando abordado pelo professor demonstra estar interado com o assunto, tem mais chances de aprender e reter os conteúdos. Ao contrário daquele que passa o tempo todo olhando para o professor, para os textos, não conversa paralelamente com os colegas, mas não consegue imprimir suas opiniões nem demonstrar seu entendimento sobre o assunto trabalhado em sala de aula.

A partir de tais resultados, entende-se que os professores acreditam que pode ocorrer aprendizagem mesmo que a focalização e a concentração não estejam necessariamente ocorrendo de forma concomitante. Porém, contrariam tal concepção quando a maioria alega que para estar atento é imprescindível que o aluno permaneça concentrado e focalizado no tema desenvolvido em sala de aula. Afinal um aluno pode não perturbar a ordem e o clima da aula, no entanto, isso não significa que esteja empenhado ativamente nas tarefas que envolvam aprendizagem. A manutenção da ordem, da disciplina e do silêncio, não é um fim em si mesmo ${ }^{23}$.

O presente trabalho não tem o intuito sugerir que os professores não estão capacitados para ensinar seus alunos, mas que precisam aperfeiçoar seus conhecimentos sobre o funcionamento da atenção, suas abrangências e conexões, para que possam descobrir maneiras de encantar ${ }^{12}$ seus alunos. E ainda refletirem sobre a necessidade de interação do aluno com o meio e com o outro, permitindo ao sujeito a construção do seu conhecimento e desenvolvimento integral, cuja interação contribui significativamente para a maturação do sistema nervoso, refletindo na qualidade das relações interacionais que o indivíduo estabelecerá ao longo da vida, fundamental para o desenvolvimento humano. Além de reforçar a importância que o processo de significação tem para a efetivação e consolidação da aprendizagem ${ }^{15,24}$.

\section{CONCLUSÃO}

Pode-se concluir por meio da presente pesquisa que os professores da escola participante, apesar de diferenciarem bem a desatenção do Transtorno de Déficit de Atenção, aspectos esses evidenciados nos resultados, demonstram um conhecimento inconsistente sobre os desdobramentos da atenção e desatenção, que são elementares para subsidiar uma prática mais adequada, no sentido de envolver efetivamente seus alunos. Assim este estudo demonstrou a superficialidade do conhecimento dos professores sobre questões que envolvem atenção na sala de aula.

\begin{abstract}
Purpose: To identify the knowledge and the concepts established by teachers about attention and its relationship to learning. Methods: The methodology used in this study was a survey and analysis of data collected by using a multiple choice questionnaire. The questionnaire had 4 questions regarding the practical attitudes of teachers about inattention and 8 questions regarding teachers' knowledge about attention, in which it was given a score. Data were analyzed qualitatively and quantitatively, by means of a descriptive statistical analysis and applying the nonparametric Kolmogorov-Smirnov test for analyzing data distribution. Results: The results of this research showed that teachers, although knowing that there is difference between Attention Deficit Disorder (ADD) and inattention, have difficulty in identifying situations in which there are ADD and inattention, differentiating the dispersion and distraction, in order to identify situations involving attention and the factors that limit it. Conclusion: the teachers who took part in the survey gave evidence of inconsistent knowledge about the unfolding of attention and inattention, which is fundamental for subsidizing the daily practice.
\end{abstract}

KEYWORDS: Attention; Teaching; Learning 


\section{REFERÊNCIAS}

1. Kastrup VA. Aprendizagem da atenção na cognição inventiva. Psicol Soc. 2004; 16(3):716.

2. DSM - IV - TR. Manual Diagnóstico e Estatístico de Transtornos Mentais. trad. Bastista $D-4 \stackrel{\text { a }}{\text {. ed. }}$ Porto Alegre: Artes Médicas; 1995; p. 79 - 84.

3. Poeta L S, Rosa-Neto F. Evaluación motora en escolares con indicadores del trastorno por déficit de atención/hiperactividad. Rev Neurol 2007; 44 (3): 146-149.

4. Castañeda-Cabrero C, Lorenzo-Sanz G, CaroMartínez E, Galán-Sánchez J M, Sáez-Álvarez $J$, Quintana-Aparicio $P$, Paradinas-Jiménez $F$. Alteraciones Electroencefalográficas en niños con transtorno por déficit de atención con hiperactividad. Rev Neurol. 2003; 37(10):904-8.

5. Rohde L,Halpern R. Transtorno de defict de atenção/ hiperatividade: atualização. Jr.Pediatr. (Rio de J.), abr. 2004, vol 80, no 2, supl., p 61-70.

6. Ramos-Quiroga JA, Ribasés-Haro M, BoschMunsó R, Cormand-Rifà B, Casas M. Avances genéticos en el trastorno por déficit de atención/ hiperactividad. Rev Neurol. 2007; 44(Supl 3):S51-S2.

7. Miranda-Casas A, Grau-Sevilla D, MarcoTaberner R, Roselló B. Estilos de disciplina en familias con hijos con trastorno por déficit de atención/hiperactividad: influencia en la evolución del trastorno. REV NEUROL 2007; 44 (Supl 2): S23-S25.

8. Vaquerizo-Madrid JV. Hiperactividad em el niño preescolar: descripcion clínica. Rev Neurol. 2005; 40(Supl 1):S25-S32.

9. Muñoz-Céspedes JM. Attention and executive processes in neuropsychological rehabilitation of the visuospatial processes. Rev Neurol. 2004; 38(5):487-95.

10. Blázquez-Alisente JL, Paúl-Lapedriza $\mathrm{N}$, Muñoz-Céspedes J M. Atención y Funcionamiento ejecutivo en la rehabilitación neuropsicológica de los procesos visuoespaciales, Rev Neurol 2004; 38(5):487-495.

11. De-Nardin MH, Sordi RO. Um estudo sobre as formas de atenção na sala de aula e suas implicações para a aprendizagem. Psicol Soc. 2007; 19(1): 99-106.

DOI: 10.1590/S1516-18462010005000101

RECEBIDO EM: 03/09/2008

ACEITO EM: 01/10/2009

Endereço para correspondência:

Rua São Manoel, 80

Campinas - SP

CEP: 13040-079

E-mail: nataliamicaroni@terra.com.br
12. Cury AJ. Pais brilhantes, professores fascinantes. Sete hábitos dos bons professores e dos professores fascinantes: bons professores são eloqüentes, professores fascinantes conhecem o funcionamento da mente. Rio de Janeiro: Sextante; 2003. p.57-63.

13. Capellini SA, Tonelotto J MF, Ciasca S M. Medidas de desempenho escolar:Avaliação formal e opinião de professores. Rev. Estudos de Psicologia, PUC-Campinas, v. 21, n. 2, p. 79-90, maio/agosto 2004.

14. Capdevila-Brophy B, Artigas-Pallarés J, ObiolsLlandrich J E.Tempo cognitivo lento: ¿síntomas del trastorno de déficit de atención/hiperactividad predominantemente desatento 0 una nueva entidad clínica? REV NEUROL 2006; 42 (Supl 2): S127-S134.

15. Tunes E, Tacca MCVR, Bartholo Júnior RS. $\mathrm{O}$ professor e $\mathrm{O}$ ato de ensinar.Cad.Pesquisa 2005;126(35): 689 - 698.

16. Salles JF, Parente MAMP. Funções neuropsicológicas em crianças com dificuldades de leitura e escrita. Psicologia: teoria e pesquisa 2006; 22 (2): 153-162.

17. Zorzi J L, Ciasca S M. Caracterização dos erros ortográficos em crianças com transtornos de aprendizagem. Rev. CEFAC 2008; 10(3) :321-331.

18. Mulas F, Mattos L, Osa-Langreo A, Gandía R. Trastorno por déficit de atención / hiperactividad: a favor del origen orgánico.REV NEUROL 2007; 44 (Supl 3): S47-S49

19. Capellini AS, Ferreira TL, Salgado CA, Ciasca $\mathrm{SM}$. Desempenho de escolares bons leitores, com dislexia e com transtorno do déficit de atenção e hiperatividade em nomeação automática rápida. Rev. soc. bras. fonoaudiol. 2007; 12 (2): 114-119.

20. Barádiménez $S$, Vicuña $P$, Pineda $D A$, Henao G C.Perfiles neuropsicológicos y conductuales de niños con trastorno por déficit de atención/ hiperactividad de Cali, Colômbia Rev Neurol 2003; 37 (7): 608-615.

21. Kaplan HI, Sadock J B, Grebb J A. Compêndio de psiquiatria: ciências do comportamento e psiquiatria clínica; Trad. Batista D. Porto Alegre:Artes Médicas; 1997.p.989 - 994.

22. Barkley R A. Transtorno de déficit de atenção/ hiperatividade(TDAH): guia completo e autorizado para pais, professores e profissionais da saúde; trad. Roizman L S. Porto Alegre: Artmed;2002. p.249-267.

23. Rodrigues A.J A. Organização e a gestão do processo ensino-aprendizagem no primeiro ciclo do ensino fundamental.Rev bras educ espec 2005;11(3):429-44.

24. Asbahr FSF. A pesquisa sobre a atividade pedagógica: contribuições da teoria da atividade. Rev. Bras. Educ 2005; 29: 108-118. 